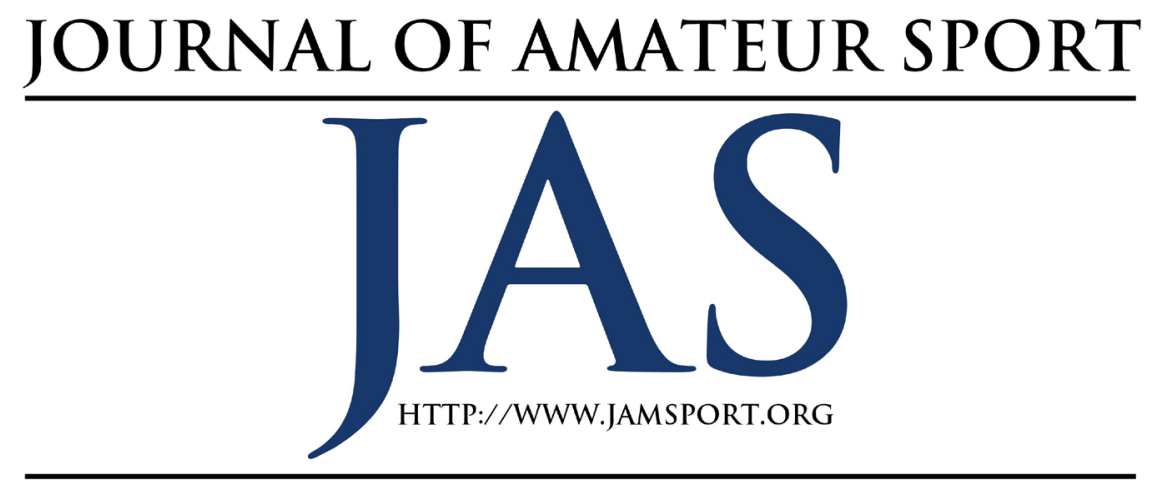

\title{
Indiana Public High School Parents' Perceptions of Interscholastic Competitive Balance
}

\author{
Gibson Stoffer \\ James Johnson
}

\author{
Khirey Walker \\ Mike Dalgety
}

Ball State University

\begin{abstract}
As part of the educational mission of interscholastic athletics, ensuring competitive balance is a priority of state athletic associations nationwide. Specifically, teams playing within a postseason championship tournament should have a fair and equitable chance to win. Private high schools, in particular, have been the focus of competitive balance scrutiny from public high school stakeholders due to disproportionately high success in many states. Despite much anecdotal scrutiny from public stakeholders, it is not clear how much they know about interscholastic policy or private school characteristics. Therefore, this study set to explore Indiana public high school parents' perceptions of interscholastic competitive balance through qualitative interview data. Using thematic analysis, five themes emerged from the data influential to competitive balance (location, policy, sport culture, financial resources, and education). Each of these themes was influenced by an omnipresent private school impact, which reinforced a need for additional education of policy and private school characteristics.
\end{abstract}

ccording to the National Fed-
eration of State High School
Associations (NFHS), the 2017-

18 academic year marked the $29^{\text {th }}$ consecutive year of increased interscholastic athletic competition within the United States (U.S.). With over 7.9 million participants nationwide (NFHS, 2018) interscholastic athletic participation is far greater than the amount of professional and collegiate participation combined. The popularity of interscholastic sport in the U.S. is unique because secondary education and athletics are combined, a model that is uncommon throughout the world where late adolescents largely rely on club or city teams for athletic competition. The purpose of U.S. in- 
terscholastic athletics is an opportunity for students to learn life skills outside of the classroom, a concept called education-based athletics (Blackburn et al., 2013). However, the goals of interscholastic athletics can be perceived differently by many stakeholders, particularly those who believe winning is a priority (Johnson et al., 2017). Furthermore, a goal of the National Interscholastic Athletic Administrators Association (NIAAA), the NFHS, and individual state interscholastic athletic associations is to provide athletes with a fair opportunity to compete during interscholastic competition (Blackburn et al., 2013).

Competitive balance $(\mathrm{CB})$ is sought by every league at every level of sport (Zimbalist, 2002) to ensure fair competitive opportunities. Given CB's economic influence in highly commercialized sport, the existing $\mathrm{CB}$ literature has focused mostly on professional and intercollegiate athletics (Fort \& Maxy, 2003). Research on $\mathrm{CB}$ within interscholastic sport is sparse, which is somewhat surprising considering the popularity of high school athletics (Johnson et al., 2017). Recently, variables such as location, geography, policy, and public/private classification have been found to increase or decrease a team's chances of winning during a state postseason tournament (Johnson et al., 2018; Johnson et al., 2017; Johnson et al., 2014; Johnson et al., 2015). Of the many variables that could impact $\mathrm{CB}$, public/ private classification has gained the most attention as evidence suggests that private schools have had disproportionate success relative to their membership (Cohen,
1997; Johnson et al., 2017; Johnson et al., 2014; Popke, 2012). In turn, private school success may be perceived as unfair by public school stakeholders, and specific policies have been adopted that are intended to mitigate such an advantage (James, 2013; Johnson et al., 2017).

As primary stakeholders, parents can be a source of frustration for athletic administrators because of their misunderstanding of policies and general lack of education regarding the purpose of interscholastic sport, yet evidence to this point remains anecdotal (James, 2013; Johnson et al., 2019; Johnson et al., 2017). As one interscholastic state athletic administrator stated, "The most intelligent person in the world can become a total fool when their kid is involved" (Johnson et al., 2017, p. 269). This issue is magnified for public school parents considering the majority of children attend public high schools $(78.2 \%$; National Center for Education Statistics, 2013). Therefore, the purpose of this qualitative study was to examine Indiana rural public high school parents' perceptions of interscholastic CB. In doing so, this study furthered inquiry into parents' understanding of $\mathrm{CB}$ and can help policymakers communicate their goals more effectively to parents and improve the interscholastic student-athlete experience.

\section{Review of Literature Competitive Balance}

There is currently no widely agreed upon definition of CB. However, literature often includes talent distribution and uncertainty of outcome as accompanying 
factors (Budzinski \& Pawlowski, 2017; Humphreys, 2002; Zimbalist, 2002). Early conceptualization of CB came from Rottenberg (1956) and Neale (1964), using professional baseball as their platform to create the Uncertainty of Outcome Hypothesis $(\mathrm{UOH})$. $\mathrm{UOH}$ is rooted in economic principles that attempt to explain fan attendance. $\mathrm{UOH}$ postulates that fan attendance increases when athletic talent is evenly distributed amongst teams and predicting a winner is challenging. Thus, CB produces uncertainty of the winner that keeps fans interested (Neale, 1964; Rottenberg, 1956). Achieving uncertainty of outcome is critical for professional sport due to the economic interests of increased consumption through ticket sales, television rights, and associated merchandise (Budzinski \& Pawlowski, 2017; Humphreys, 2002; Zimbalist, 2002). Policies such as reverse order drafts, revenue sharing, salary caps, free agency, and league scheduling are consistently implemented (Caporale \& Collier, 2015; Fort \& Quirk, 1995). In college athletics the economic variables (i.e., salary caps, revenue sharing) do not apply, and player tenures are determined by scholarship lengths rather than salaries. Intercollegiate governing bodies are tasked with finding CB policies that fit within their structures. Recruiting regulations, eligibility, conference affiliation, and compensation are commonly utilized CB policies (Dittmore \& Crow, 2010). Interscholastic sport is different from professional and intercollegiate athletics. Interscholastic athletics policies are rooted in the development of education-based extracurricular activities (Blackburn et al., 2013). Student-athletes are not paid or have long-term contracts like professional athletes. High schools are not independent for-profit businesses, meaning revenue sharing is not a concern. While there are amateur sport similarities among intercollegiate and interscholastic sports, the nationalistic vs. state policies, as well as the elevated focus on elite training, resources, and revenue differentiate these two levels of sport (Blackburn et al., 2013). With the emphasis on social and skill development, and the large number of participants, interscholastic CB cannot be ignored. Thus, for the purposes of this study, the following CB definition used by Forrest and Simmons (2002) was adopted; "a league structure which has relatively equal playing strength" (p. 229). This definition accepts the $\mathrm{UOH}$ with a specific focus on the distribution of talent rather than the economic or attendance figures emphasized in professional sport.

Johnson et al. (2015) found that each state has its own interscholastic CB policies. However, central to every state's $\mathrm{CB}$ approach is an enrollment classification system where student enrollment determines the athletic classification of schools. The total number of classifications per sport is based on the total number of schools participating in that sport. In addition to basic student enrollment, 21 states utilize a multiplier whereby targeted schools' (e.g., private schools) enrollments are multiplied by a designated number to artificially increase enrollment 
numbers for athletic classification. Multipliers are thought to alleviate inherent advantages by placing some schools in a higher enrollment classification. Multiplier numbers range between 1.3-2.0.

Eight states use a separate playoff system for nonpublic schools, isolating private and public schools from playing each other in the postseason tournament (Johnson et al., 2015). Oregon and Oklahoma use socioeconomic factors to reclassify teams, where the total number of students who receive free or reduced lunches is multiplied by a specific number (i.e., Oregon uses .25), which then causes recalculation of the total enrollment for the school. This approach is based on an assumed relationship between economic resources and interscholastic athletic success (Monahan, 2012). Finally, seven states use a success factor that targets athletic success to ensure CB. Success factors operate on the premise that overly successful schools have some characteristic that makes them consistently better, and subsequently should be subject to a formula that determines if too much success should move them up in enrollment classifications to play larger schools in post-season state tournaments.

\section{Public vs. Private}

The bulk of existing interscholastic CB literature focuses on private school success at the post-season tournament level. The disproportionate success of private schools in many states has been referred to as the public/private debate (Epstein, 2008; James, 2013; Johnson et al., 2017). While the majority of students within the U.S. attend school within a designated district, private schools are not geographically bound and enroll students who can afford tuition and meet elevated admissions criteria to attend (Epstein, 2008). According to the U.S. National Center for Educational Statistics (2018), only 5.8 million high school students, or $10.2 \%$ of high school students nationwide, attend private high schools.

Although some private schools do not provide interscholastic athletics, there is evidence of competitive imbalance in favor of private schools. Cohen (1997) was one of the first to study this imbalance by investigating 43 of the 45 state athletic associations in which public and private schools compete headto-head in state tournaments. Findings indicated that while only $13.1 \%$ of the member schools were considered private, they accounted for $18.4 \%$ of all state championships won during the 1996-97 school year. Only 13 total states had private school state championship winning percentages that were less than the percentage of private schools competing. A follow-up study conducted by Popke (2012) 15 years later using the same methods and criteria confirmed the competitive advantage gap favoring private schools had grown. In California, a state where only seven sports compete for a state championship, private schools won $53 \%$ of total state championships, despite only $26 \%$ of the schools in the state designated as private. Minnesota and South Dakota were two states found to have relatively no $\mathrm{CB}$ issues in the 
1997 study to experiencing double-digit increases in private school state championships in 2012.

Policies designed to mitigate competitive imbalance are far from perfect. States that rely only on their enrollment classification system for CB may ignore the disproportionate success held by private schools, which is magnified for small schools because private schools are often found to have the highest success in smaller classifications (Johnson et al., 2014). Socioeconomic policies presume schools with greater financial resources have a competitive advantage, but exclusive use of socioeconomic policies could lead to interscholastic athletic associations ignoring other $\mathrm{CB}$ variables that may be more effective (Johnson et al., 2015). Ironically, policies that target financial characteristics have become increasingly popular as public school funding has decreased in recent years (Chen, 2018). Finally, success factors ignoring public/private classification by targeting perennially successful athletic programs are criticized for punishing success and forcing younger students to play up a classification after previous cohorts of athletes were successful (Johnson et al., 2014; Johnson et al., 2015; Sokeland, 2012). These policies are influenced by six overlapping factors that commissioners or executive directors (C/EDs) of state athletic associations identified most influential in $\mathrm{CB}$ policy construction: size (i.e., enrollment), geography (i.e., location), wealth, tradition/community support, and public misunderstanding (Johnson et al., 2017).
Indiana Interscholastic Competitive Balance

The specific CB context within Indiana is important because this is the state where a large amount of disproportionate private school success occurs, and where a baseline of literature exists to provide context for the current study (Johnson et al., 2014; Johnson et al., 2015). The Indiana High School Athletic Association (IHSAA) utilizes an enrollment classification system. Most sports contain four classifications (1A-4A) with $1 \mathrm{~A}$ the smallest enrollments and $4 \mathrm{~A}$ the largest. Soccer has the fewest number of classifications (1A-2A) and football the most (1A-6A; IHSAA, 2019). Indiana is one of seven states that utilizes a success factor as a supplemental CB policy combined with enrollment classifications. The success factor has been modified multiple times, and the Tournament Success Factor (TSF) was finalized in 2012. The current format of the Indiana TSF is as follows; every IHSAA team sport football, volleyball, soccer, and boys/girls soccer and basketball - is eligible to play in the post-season state championship playoff tournament. Points are assigned to teams based on their tournament success; a sectional championship earns one point, a regional two points, a semistate three points, and a state championship four points (IHSAA TSF, 2016). A reclassification period occurs every two years, and teams that have earned six or more points are moved up one enrollment classification for the next cycle. Reclassified teams stay in their elevated classification if they score three to five points in the specific sport over the dura- 
tion of the next two years, but are moved back down if the team scores two points or less. Reclassified teams can also be moved up an additional classification if they achieve six or more points.

Indiana's TSF was heavily influenced by football, largely in part to the level of private school dominance within the sport. Before the TSF, private schools accounted for $40 \%$ of the state championships, while only accounting for $14 \%$ of the member schools competing (Monahan, 2012). During this time, one high school journalist wrote, "quite simply, I'm fed up with watching parochial schools dominate the state finals-and I'm fed up with the IHSAA's apparent indifference towards the problem" (Gaskins, 2012, para 3). In a case study conducted by Johnson et al. (2014), every playoff tournament champion and runner-up in every sport from 1997-2013 were examined to provide the scope of Indiana interscholastic CB. Class designation, district, location (rural or metropolitan), and public/private status of the winners and runners-up were also identified. Johnson et al. (2014) found that similar to other states, there was disproportionate success by private schools, specifically in the middle to lower enrollment classifications. Private schools accounted for $32.9 \%$ of the total championships won per year, while only accounting for approximately $14 \%$ of competing member schools. Additionally, although the TSF does not directly target private schools, 21 of the 37 schools that were reclassified were private (IHSAA, 2019).

\section{Parents and CB}

The magnification of private school success may encourage inaccurate perceptions of CB from stakeholders. These perceptions often originate from a misunderstanding of how private schools operate and can lead public school stakeholders to believe their schools are at an athletic disadvantage (Epstein, 2008; James, 2013; Johnson et al., 2017). As Johnson et al. (2017) stated, "There are certainly wealthy nonpublic schools with lavish facilities and successful athletic programs. There are also nonpublic schools that struggle to operate and can hardly fill athletic teams" (p. 259). There also appears to be a belief, at least anecdotally, that private schools recruit students for athletic purposes (Himmelsbach \& Thamel, 2012; James, 2013; Johnson et al., 2018). Every state athletic association have rules that prohibit interscholastic athletic recruitment, but recruiting appears to be a widely-held perception by critics. State athletic associations know that transferring for athletic reasons disrupts $\mathrm{CB}$, which is why the U.S. court system routinely rules in favor of state associations enforcing their transfer and recruiting rules (Johnson et al., 2018). Unfortunately, instances of dubious transfer and recruitment exist, but the motives for student transfer are difficult to prove and require investigations to determine interscholastic eligibility.

Some parents may perpetuate these recruiting beliefs and become a challenge for athletic administrators (Johnson et al., 2017). Moreover, research has found parents to be the driving force behind 
CB concerns and lawsuits (Evans, 1993; Johnson et al., 2019; Johnson et al., 2018). Parents have a profound impact on the involvement and enjoyment of their children within interscholastic sport (Bosma \& Kunnen, 2001; Johnson et al., 2019; O’Neil, 2015), making them a key influencer of athletic policies. Considering the high level of parental involvement at the interscholastic level, it is noteworthy that parental misconceptions can cause issues for athletic administrators and coaches. C/EDs consistently acknowledge one of their biggest challenges was a lack of knowledge and misunderstanding by the public, and this confusion is often fueled by over-involved parents (Johnson et al., 2019; Johnson et al., 2017). Additionally, while there is often adequate interaction between parents and coaches relative to the progress of the student-athlete, there is a scarce amount of communication between parents and athletic administration, potentially causing a disconnect about CB policies (Camire, 2014).

It is understandable that some parents can be misinformed/underinformed about interscholastic CB. It is important to note, however, perceptions of parents are largely anecdotal. Although state athletic administrators believe parents are underinformed (Johnson et al., 2017), no empirical studies have confirmed parents' actual knowledge about $\mathrm{CB}$ or private schools, despite the frustrations they seem to cause. Therefore, the purpose of this study was to fill this particular knowledge gap by revealing the perceptions on interscholastic CB from Indiana rural public high school parents.

\section{Method}

Based on the goals of this study, the benefits of qualitative phenomenological research were most appropriate. Qualitative research is designed to fill gaps in knowledge and encourage new ways of addressing issues or lines of thought from understudied or misrepresented groups (Creswell, 1998). Additionally, qualitative methodology is able to create theoretical propositions rather than test established theories as quantitative research would do. A phenomenological approach allows the researchers to objectively evaluate human phenomena by removing preconceived notions. These approaches were used under a broad philosophic worldview of constructivism whereby knowledge of the phenomenon was created through historical and social norms (Creswell, 1998).

\section{Positionality}

The lead researcher/interviewer attended a mid-sized public Midwest high school outside of Indiana that did not include a tournament success factor. Their state did not have the disproportionate private school success that exists in Indiana. The lead researcher does have a master's degree in sport management, but was unfamiliar with Indiana's post-season tournaments until conducting this study. They played three sports in high school and can speak knowledgably about many sports. In essence, the lead researcher was an ideal candidate to conduct the interviews because of their sport expertise and lack of bias regarding 
Indiana's post-season competitive balance structure or private school success.

\section{Interviews}

Interviews are helpful at attaining a participant's opinions through descriptions of their own experiences and allow researchers to gain a range of ideas or feelings that people have about something, which can help policymakers understand the criteria needed for successful rules, laws or policies (Creswell, 1998). Moreover, interviews enable the researcher to gain in-depth responses and provide the background of thoughts and feelings (Kvale, 1996). Specific to this study, results would help state policymakers better understand how public school parents perceive various $\mathrm{CB}$ issues, with particular attention on how public school parents understand private schools. This knowledge could help create interscholastic CB policies, as well as guide educational materials delivered to stakeholders.

Parents from somewhat small (2A) to somewhat large (3A) Indiana public high schools (team sports classifications) lo-

Table 1

Participants

\begin{tabular}{|c|c|c|c|}
\hline Participant & Gender & Sport(s) Played by Child & $\begin{array}{c}\text { School } \\
\text { Classification }\end{array}$ \\
\hline Participant \#1 & Female & Boys Golf, Volleyball, Girls Tennis & $2 \mathrm{~A}$ \\
\hline Participant \#2 & Female & Boys Basketball, Boys Soccer, Softball & $3 \mathrm{~A}$ \\
\hline Participant \#3 & Male & $\begin{array}{l}\text { Boys Swimming, Boys Tennis, Girls } \\
\text { Swimming }\end{array}$ & $3 \mathrm{~A}$ \\
\hline Participant \#4 & Male & $\begin{array}{l}\text { Football, Boys Basketball, Boys Golf, } \\
\text { Boys Soccer, Boys Swimming, Volleyball }\end{array}$ & $3 \mathrm{~A}$ \\
\hline Participant \#5 & Male & $\begin{array}{l}\text { Boys Basketball, Boys Tennis, Volleyball, } \\
\text { Girls Tennis }\end{array}$ & $2 \mathrm{~A}$ \\
\hline Participant \#6 & Female & $\begin{array}{l}\text { Boys Basketball, Boys Tennis, Volleyball, } \\
\text { Girls Tennis }\end{array}$ & $2 \mathrm{~A}$ \\
\hline Participant \#7 & Male & Volleyball, Girls Track/Field & $3 \mathrm{~A}$ \\
\hline Participant \#8 & Male & Softball, Volleyball, Girls Basketball & $2 \mathrm{~A}$ \\
\hline Participant \#9 & Male & $\begin{array}{l}\text { Baseball, Football, Wrestling, Volleyball, } \\
\text { Girls Basketball }\end{array}$ & $3 \mathrm{~A}$ \\
\hline Participant \#10 & Female & Boys Basketball, Volleyball & $3 \mathrm{~A}$ \\
\hline Participant \#11 & Female & Baseball & $2 \mathrm{~A}$ \\
\hline Participant \#12 & Female & $\begin{array}{l}\text { Volleyball, Girls Basketball, Girls Soccer, } \\
\text { Girls Tennis }\end{array}$ & $3 \mathrm{~A}$ \\
\hline Participant \#13 & Male & $\begin{array}{l}\text { Baseball, Football, Boys Basketball, } \\
\text { Volleyball }\end{array}$ & $3 \mathrm{~A}$ \\
\hline
\end{tabular}


cated in Indiana were selected for participation. A total of 13 participants from eight different schools were interviewed before data saturation occurred, which justified the size of the data set (Creswell, 1998). All participants had children who were juniors or seniors currently playing a varsity sport. A listing of participants appears in Table 1.

Classifications were chosen based on prior research of Indiana and its CB history by Johnson et al. (2014), which found that private high schools' success is most prominent in smaller and midsized enrollment classifications. Purposeful sampling was used to identify participants through athletic director referrals of parents who met the inclusion criteria. Participants were found throughout the middle third of the state, allowing representation of public schools with varying amounts of post-season success in different sports. Although external validity is not a goal of qualitative research, the participants' schools resembled rural public schools found throughout the state of Indiana.

\section{Data Collection}

Athletic directors were initially contacted to provide contact information for parents who had children competing in the post-season tournament within the last two years. Athletic directors were not informed of the detailed questions, only that the researchers would be asking about general competitive balance topics. Following the collection of emails or phone numbers gained through nominations and recruiting efforts, parents received an invitation asking them to participate in a study regarding their impressions of interscholastic athletics. They were instructed through the recruitment email to complete a basic demographic questionnaire. Parents who held positions within interscholastic athletic administration or coaching were excluded from the study. After a sufficient number of participants responded, interviews were scheduled based on a time and location that best fit within their schedules. A digital voice recorder was used to collect data during the interviews, as well as during post-interview transcription. Upon arrival, participants were asked to complete a consent form where the IRB-approved terms of confidentiality and participation were clarified.

After consent was given, the lead researcher started the recorder and explained their role as the moderator. Those roles included asking semi-structured questions, probing with follow-up questions, and listening to the participant's responses (Creswell, 1998). After the introduction, the lead researcher used a prepared list of questions to generate discussions about interscholastic CB (see Appendix). At times the lead researcher probed further to gain a perspective on an issue, recovered conversation if it deviated from an intended subject, and moved from one question to the next (Creswell, 1998). The interviews lasted from 30 to 60 minutes. When the researcher successfully navigated through the list of questions, the participants were thanked for their time, and the interview concluded. 


\section{Data Analysis}

Thematic analysis guided the development of this study and is an effective method for systematically identifying, organizing, and analyzing emergent themes from a collection's behavior of a phenomenon, which is often derived from the use of interviews (Braun \& Clarke, 2019). In this particular study, thematic analysis was used to determine the collection of perceptions of public high school parents on interscholastic CB. A general inductive approach was utilized for data analyzation (Thomas, 2006). An inductive approach is often used within qualitative studies, specifically with thematic analysis. The inductive theory approach condenses data into summary format in order to generate connections between the research objectives that arose from the data set and to generate or apply a theory about the experiences that are apparent within the data set (Thomas, 2006).

Interviews were transcribed verbatim and were reviewed multiple times by the lead author with the help of a CB expert who helped generate multiple perspectives and add multivocality in the selection of quotes and consensus themes (Patton, 2002). Trustworthiness (Creswell, 1998) was established using member checking, whereby transcripts were sent to participants to ensure transcripts were accurate. Participants were asked to add or clarify information from their interviews. No modifications were made by any participants. Open coding was initially used to organize the data through labeling the concepts, perceptions, or issues based on their characteristics (Khandkar, 2017). Once finished, the lead researcher used each labeled Word document to write a descriptive summary that ciphered what was said about each phenomenon or issue, and reported any themes that emerged through their discussion (Thomas, 2006). Themes refer to recurring patterns across the data in relation to a fundamental concept. In this study, it would be considered public high school parents' perceptions of interscholastic CB. Themes were determined and justified by their significance and triangulated with input from a CB expert (Maguire \& Delahunt, 2017).

When the descriptive summaries were completed, the lead researcher reviewed the summaries to determine what themes cut across the sections. A final report to represent parent perceptions of interscholastic $\mathrm{CB}$ issues was then created (Thomas, 2006). Axial coding was then used as a more direct approach to data analysis to make connections between all of the themes that emerged (Denzin \& Lincoln, 1994). Axial coding involves the use of the researcher's progressed current knowledge of concepts to affirm the accuracy of their representation and explore relationships among the concepts and labels. This process allowed the researcher to separate the data and reassemble them in new, like ways.

\section{Findings and Discussion}

Through the interviews of public school parents and ensuing thematic analysis, several noteworthy themes 
emerged. It was anticipated that themes might emerge as isolated concepts, each with its own impact on CB. Independent themes are a common finding in qualitative research (Creswell, 1998). Instead, five themes (e.g., policy, location, financial resources, sport culture, education) seemed to be influenced by one higher order theme (public vs. private) that was consistently present within each individual theme. Participants could rarely discuss any facet of $\mathrm{CB}$ without acknowledging private school influence, which drew comparative analyses between public and private schools throughout. Although inductive thematic analysis is not necessarily intended to create theory, a model generated from the results appears in Figure 1.

\section{Higher Order Theme - Public vs. Private}

The higher order theme that consistently emerged throughout the entire analysis, particularly throughout the analytic coding process, was public vs. private influence. Thematic analysis uses patterns of "conversation topics, vocabulary, recurring activities, meanings, feelings, or folk saying and proverbs" (Taylor \& Bogdan, 1984, p. 131) to justify emerging themes (Braun \& Clarke, 2019). While some comments were direct, and others more incidental, nearly every participant's perception of CB was shaped through a comparative view of public vs. private schools. Most comments were built on the assumption that private schools are inherently more affluent and resource-rich than their public coun-

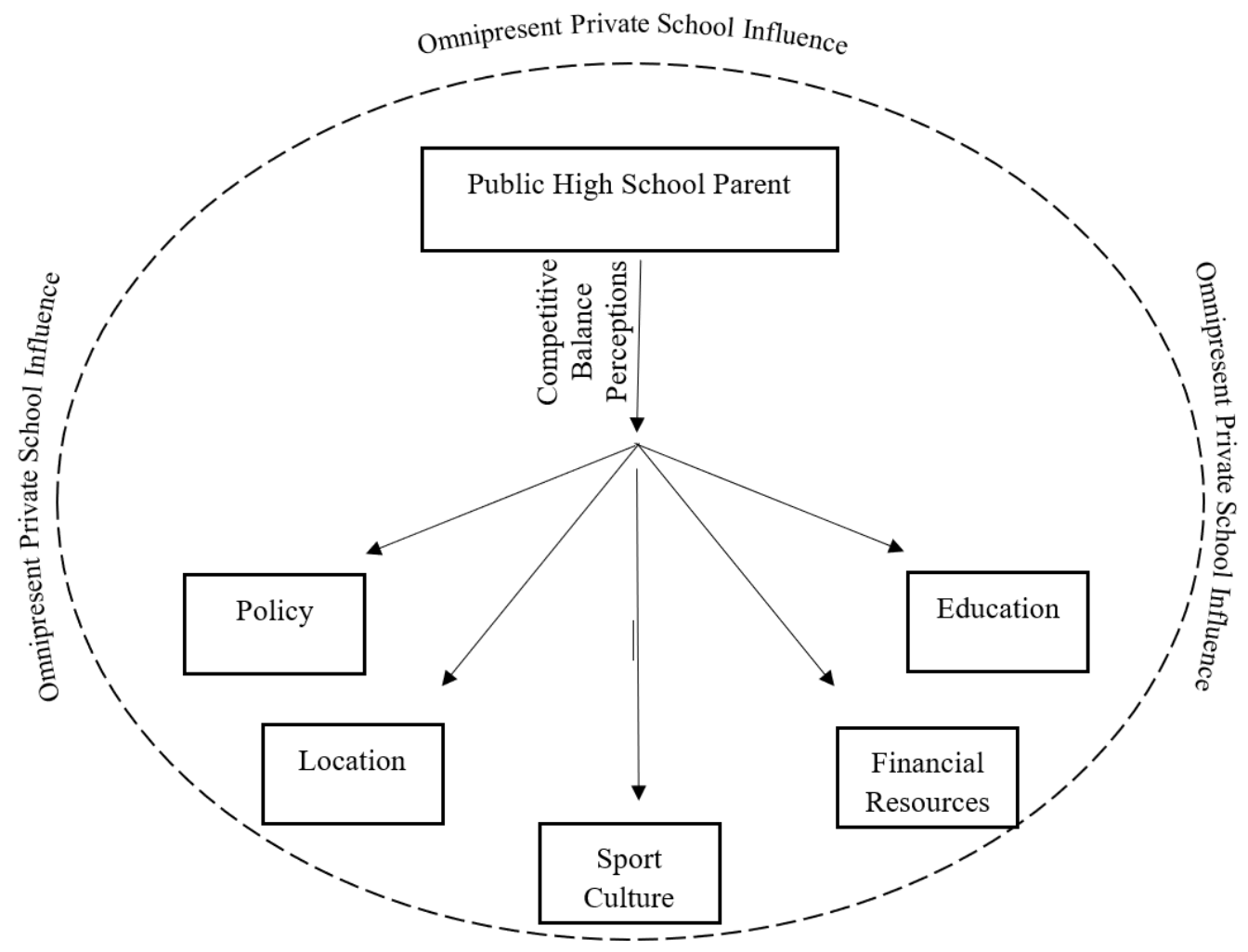

Figure 1. Public/Private Omnipresent Model 
terparts. This higher order theme was magnified in part due to the participant sample. All participants resided within Indiana's District 2 (middle third of the state that includes Indianapolis), where metropolitan private school success is found to be the highest (Johnson et al., 2014).

Additionally, each participant's child competed at a school with small to midsized enrollment classifications where private school postseason success was found to be the highest and often lead to beliefs of athletic disadvantages by public school stakeholders (Johnson et al., 2014). As Participant 4 stated, "I've said it since I was a student myself, they just have an unfair advantage. I see private schools taking the lead in the championships. So, there's got to be some way for it to make it equal." Until now, this point has not been verified. Within the state of Indiana, this notion is logical considering that private schools account for nearly $33 \%$ of total championships won per year while only accounting for $14 \%$ of competing member schools (Johnson et al., 2014).

One could argue that the crux of the issue is because of private schools and their lack of geographic boundaries, which often coincides with accusations of recruitment. As Participant 8 noted, "Yes, the advantage is that [private schools] can actually go out and recruit the studs, the Division I players, the five star recruits, even the four star recruits. That is the single largest advantage." Frequently, the participants seemed to be influenced by this notion, connecting athletic recruiting to private schools in nearly every theme. This recruiting belief has been a dominant issue nationally as well (Smith, 2018; Thomas, 2017). Some parents report the rise in club sports could offer private school coaches an opportunity to recruit attractive athletic talent at younger ages before any rules are applied to their eligibility. Or, private schools could use resources to allow public school athletes reduced tuition rates or scholarship opportunities (Himmelsbach \& Thamel, 2012). Whether the reason is recruiting, better resources, or some other perceived advantage, participants believed their children's chances to win a state title were often unfairly impacted by private schools. These beliefs were omnipresent as participants spoke about the other themes.

\section{State Specific Policy}

The first emergent theme was the importance parents place on the influence of CB policy. While some parents had indifferent reactions regarding Indiana's TSF, seven of the 13 parents had a negative perception of the current policy. In fact, when asked about one of the biggest problems within high school sports, Participant 9 was quick to point out the TSF: "I think one of the most hideous things that the IHSAA's ever done is the success factor. Whoever designed that just absolutely does not have a clue, really. What part of it has to fail? Everybody thinks that's stupid." Literature on success factors suggest a perception that such policies are unfair because teams are being punished for success, and the 
resulting re-classification would be unfair for future student-athletes (Johnson et al., 2014; Sokeland, 2012). This frustration seemed especially true for those who have been affected by the TSF and were moved up a classification: "I understand the premise behind it, but we are a $3 \mathrm{~A}$ volleyball program, we just won the $4 \mathrm{~A}$ title, first time ever. What do we do now? We had some incredibly talented athletes, but now they're graduating" (Participant 10).

Participants also acknowledged the impact of a few sports that drive $\mathrm{CB}$ policy. Traditionally, football has been central to the national $\mathrm{CB}$ discussion because it has the most athletes playing the sport (over 1 million; NFHS, 2019) and can oftentimes be seen as the center of community pride (Coakley, 2016). Indiana's success factor was heavily influenced by the football community. Multiple participants followed this logic:

I think you're in a class, that's where you should be, but due to our success we bumped up, participated against higher level, bigger schools have more athletes to choose from to make a team. To me, that's a football thing and a parochial school thing. (Participant 7)

While football was noted as a driver of policy, some participants longed for previous $\mathrm{CB}$ structures while they lamented over the loss of single class sports. Indiana changed from single-class tournaments to enrollment classifications in 1998, and six participants would like to see it make its return, specifically within basketball. At one time, Hoosier Hysteria pitted all schools against each other in a winner-take-all basketball tournament and was immensely popular among players and spectators. Although participants acknowledged that the classification system makes it fairer for all teams competing for a state championship, some still longed for the nostalgia and fan-centric nature of a previous policy where $\mathrm{CB}$ was not at the forefront:

You know, a lot of people are completely against class basketball. I saw something on Twitter this past weekend, and it showed this packed Hoosier Dome... it was completely packed, and it was when there was one tournament champion. Who cares if it was so unfair? (Participant 1)

Omnipresent Private School Influence on State Specific Policy

Ironically, the participants who wanted a single-class system that was competitively imbalanced simultaneously attacked private schools for causing $\mathrm{CB}$. When asked if the IHSAA needs to address private school success from a policy perspective, Participant 13 was one of many who mentioned they would like to see action: "I see private schools taking the lead in the championships. So, there's got to be some way to make it equal, but I don't know." These sentiments to curtail private school success through policy is where omnipresent public/private perspective influence was often noted. Some participants failed to realize that Indiana's TSF has indirectly 
targeted private schools' disproportionate success, and the majority of schools (21 of 37) that have been re-classified were private schools (IHSAA, 2019). Additionally, the participants seemed to be unaware of the legal and political hurdles that state athletic C/ED's face when trying to directly address private schools with a specific policy. For example, Ohio attempted to pass a new CB initiative that was approved as early as 2014 , yet was halted due to multiple legal battles before it was finally passed at the start of the 2018 academic year (McCurdy, 2018). Even if the IHSAA attempted to implement a $\mathrm{CB}$ policy that further addresses private school success, some may still be unsatisfied. For example, the Alabama High School Athletic Association, which utilizes a multiplier, consistently receives negative feedback from stakeholders regarding its policy, despite it being the most aggressive towards private school dominance (Thomas, 2017).

In summation, the majority of participants were critical of the current CB format known as the TSF; however, most acknowledged they did not completely understand the policy. Their preference was for policy to focus more on private school dominance, or to create a completely new CB policy. Admittedly, however, the participants lacked knowledge needed to have well-informed opinions on new policy creation.

\section{Location}

Location often has a direct influence on CB. Within Indiana, sectional matchups are based on geography and not seeding. Therefore, sectional matchups could feature some of the best teams in the state facing off in the early rounds of the tournament rather than in the later rounds. These geographical matchups place pockets of schools with strong programs in the same sport at a disadvantage for moving out of sectional competition and further into the state tournament. Participant 4 mentioned the following regarding the first round of the playoffs, "Yeah, you know, volleyball and [our] county. I mean, I still feel like the two best teams ended up there or came close to ending up there in the end, but it's just a tough sectional."

\section{Omnipresent Private School Influence on Location}

While the geographic location of schools was mentioned frequently regarding $\mathrm{CB}$, the conversation was often dominated by the location of students in regards to transferring, recruiting, and open enrollment. Specifically, the participants seemed to be affected by the public/private influence and noted that location was a critical component of private school success. Participants were asked to clarify how public and private schools are recruiting student athletes, and the majority of responses involved private schools waiving tuition or providing scholarships through a lottery. Others believe parents will be dishonest about their living situation or address:

People try to bend the rules all of the time. They go live with their uncle or their aunt, or somehow get a new address in that area, 
even if they maybe not truly live there to try and move to a better program or someplace where they are going to win. (Participant 4) While these athletic recruiting beliefs appear to be widespread from public school parents, it is critical to remember that every state athletic association has rules against athletic recruiting (Johnson et al., 2018). Nonetheless, throughout the interviews second-hand stories regarding private school athletic recruitment were abundant. Participant 12 shared a personal instance regarding a private school interaction about athletics:

We moved to [our] county from out of state... I was making calls with different schools to set up times that I could come observe, take a look, and I called a parochial school and said I have three daughters, here are their ages, we would like to come observe, and their first question was 'do any of them play volleyball?' Not 'was I Catholic?' Not, you know, 'what are you looking at, for academics?' I was coming from the outside, and that was so silly to me... Now after living in that community, I'm like ok, now I know why they asked that question. But I mean, that's concerning.

While their story highlights the unfortunate reality that some within interscholastic athletics may prioritize winning above academics, it would be difficult to argue that it is a direct recruiting violation. These stories are not new. Private schools are routinely at the forefront of recruitment accusations (Epstein, 2008; Hammelsbach \& Thamel, 2012; Johnson et al., 2018).

Finally, when asked where the IHSAA governance needs improvement, one of the most common responses was more investigation or policing on transfers and recruitment. This suggestion was accompanied by the acknowledgment that is difficult to determine if a transfer is solely because of athletic purposes. Participant 8 said:

There's always some way to beat the system. There will always be a way. I don't know if you could ever totally, completely police it. In most cases if you policed it too much, I think you're hurting the kid when it's not technically the child that's making the decision. Ironically, states like Indiana that utilize open enrollment policies have seen a slight shift in this narrative (Corso, 2018; Popke, 2012). Open enrollment allows public school students to attend any school they choose, with some minimum conditions. Within Pennsylvania, for example, both public and private non-boundary schools have accounted for $73 \%$ of all boys' basketball, $60 \%$ of girls' basketball, and $56 \%$ of football state championships over the past seven years (Corso, 2018). Parents now seem to acknowledge that open enrollment has minimized some of the recruitment accusations towards private schools. When Participant 7 was asked if private schools recruit student athletes, they responded with: "I think that used to be the way. I mean, I think it's been fair game for 
everyone." Even with open enrollment parents still acknowledge the long-standing tradition of going to school in the location they live and moving for athletic purposes as something students at private schools do most often. The value of playing for your town or school appears to still be entrenched enough to perpetuate private school recruiting accusations.

\section{Financial Resources}

Although there are no empirical findings that link wealth with interscholastic athletic success, public school parents felt that the most financially privileged schools generate the most wins. In fact, 10 of the 13 participants within the study cited financial resources as a prohibitive factor for public school athletic success. In Indiana, schools within metropoli$\tan$ areas have more success than those within rural locations (Johnson et al., 2014). One explanation from participants was the greater financial resources within more populated areas, and particularly for private schools. As the Michigan High School Athletic Association commissioner put it, "Those that have money have nicer facilities, more stable coaching staffs, parents are able to get private lessons in golf and tennis or softball pitching or free throw shooting or passing" (Johnson et al., 2017, p. 268). Participant 2 agreed: "I think money is an issue. When you have schools that are in wealthier districts, where the money is available, and the school, the program tends to be supported also. The parents can be and will be more involved." Beyond Indiana, the Florida High School
Athletic Association noted the same ideas and argued the debate should not be focused entirely on the public/private issue, but rather a combination of wealth and geographic differences (Hale, 2017). In Florida $67 \%$ of the state team championships are won by schools located within one of the eight largest metropolitan areas.

Some of the participants suggested the IHSAA should look into adopting a similar position as Oregon and Oklahoma and implement a socioeconomic $\mathrm{CB}$ policy. When asked how the IHSAA could improve the postseason tournament, Participant 8 suggested to further investigate socioeconomic factors on $\mathrm{CB}$ : "We're well over $50 \%$ free or reduced in a school district of probably 1,150 kids... why don't you find someone that's done that [implemented a socioeconomic policy], and has had success with it, and let's see what we can do for our kids." However, determining the correct parameters of wealth is difficult, and while it is reasonable to assume wealth contributes to athletic success, limited evidence exists to inform policy (Johnson et al., 2017; Monahan, 2012).

\section{Omnipresent Private School Influence on Financial Resources \\ With the majority of participants acknowledging that wealth could be an indicator of interscholastic success, they were quick to link private schools to wealth: \\ "I think from a funding stand- point that there's a great differ- ence. Because of private funding}


they [private schools] tend to have better facilities, better schools, whether sports facilities or the school itself seem to have a level up on those things" (Participant 4).

Disproportionate financial resources often exacerbate the public/private debate, yet this advantage may be an inherent characteristic that private schools enjoy over their public school counterparts without much hope of change. Cohen (1997) once mentioned that public school students "tend to come from wealthier backgrounds, families who can afford membership at the finest fitness facilities and extras" (para.1). Participant 6 agreed:

A private school, you're paying tuition, then I think that it automatically puts you into an entirely different bracket than public. Even if you have a lottery system or you have scholarships for students, you're typically going to have more privileged groups or audience capital in that school corporation... private is not always going to equal public.

Despite the perceived link between athletic success and private school wealth, it is important to note some private schools do not have lavish resources or athletic success, while some public schools in affluent school districts may have similar resource advantages. As the Michigan athletic commissioner once mentioned, "It's not an issue anymore-public and nonpublic schools - it's haves and have nots... Because the biggest predictor of success is money. All of these success factors and multipliers- the biggest factor is money" (Johnson et al., 2017, p. 268).

\section{Sport Culture}

Above any other variable, athletic success was explained by participants as the product of the culture built within their athletic program. All participants stated the culture of the program is the core ingredient for successful athletic programs, and the variable that could overcome competitive imbalance (and private school advantages). In discussion with the participants, it became apparent that three components are believed to build a successful athletic culture. The first and most important step is coaching:

They have their hands in things from kind of the ground level up, and really stay consistent in how they do things, and do it well. I think that difference can be seen more glaringly at the high school level at times than in college, or pro, but you see that good coaches make a difference. (Participant 4) This point is critical because of the ability of private schools to generally attract better coaches due to the resources and facilities not often found at public schools (Epstein, 2008). The next component in making a successful sport culture identified by parents were feeder programs (i.e., grassroots programs). As many of the participants noted, club or travel teams contribute to athletic success at the high school level, but it is the feeder programs that instill fundamentals, 
and club teams led by high school assistant coaches can build on prior success:

I will say for the ones that have had a lot of success, it seems to be their elementary programs, their feeder programs. If that is strong, they have strong coaches, and it's a top down approach, they're using the same system or style of coaching. (Participant 12)

These points are pivotal to the public/ private debate because it is often wealthy private school programs with long histories of success that have resources, coaches, and facilities to achieve such feeder programs (Epstein, 2008). Public schools, too, can have such programs, but the participants said it was more difficult to sustain these resources at public schools.

The final step in the process is the community support, which can create a historical tradition within a school that becomes a part of its fabric that cultivates success (Coakley, 2016). Participant 10 stated that community support has benefits beyond the field of play:

When it is a community venture it makes it so wonderful, for both the players and community. There were people that would come to volleyball that didn't have kids participating, they loved being there to be able to support, just to have something to do.

Competitive balance allows for the aforementioned traditions and community to emerge through the inclusion of more participation and skill building. These developmental advantages of ensuring competitive balance are what set interscholastic athletics apart from professional competitive balance policies.

\section{Omnipresent Private School Influence on Sport Culture \\ Participants generally agreed that a} successful sport culture was a positive influence both on the field and throughout education-based interscholastic athletics. However, participants also acknowledged some concerns. Even if private schools do not overtly recruit student athletes, some participants indicated the culture of traditionally-successful sport programs within private schools naturally incentivizes athletically-gifted student-athletes to attend private schools. This may be counter to the educational mission of interscholastic athletics, yet some seemed to understand these motives:

I mean, but again, you get the tradition that is behind it, and you know, [a successful private school] for instance for volleyball, they're a Catholic school. The people want to go there because they had such a great coach, and she left this legacy, and if that's what you feel like is best for your child, then go for it. (Participant 10) These perspectives demonstrate the importance of sport culture on the development of young athletes, and the difficult decision some parents have when considering where their child might attend high school. While most of the participants in this study did not have geographical access to a perennially successful private school, they acknowl- 
edged that sport culture was the most important variable likely to neutralize such advantages.

\section{Need for Education}

Participants seemed to have strong convictions regarding interscholastic athletics and $\mathrm{CB}$, yet it became apparent that participants lacked knowledge of the larger interscholastic athletic mission or specific policies. For example, a few of the participants were unaware of Indiana's CB structure, such as Participant 8: "It's funny that you ask this question, I actually a week ago was on the IHSAA site going to go find how to determine the success factor. Just for my own good... I really wish I knew more about it." Yet, a lack of understanding did not stop some participants from sharing an instant opinion. It became apparent that most of the parents who were aware of the TSF were the ones affected by it personally. One could consider it contradictory that while the majority of parents have a negative perception of the TSF, the same percentage of participants were unaware of it. This supports the interscholastic state athletic association C/ ED's perception within Johnson et al.'s (2017) study, which noted that a public misunderstanding presents a major challenge to $\mathrm{CB}$ policies.

$\mathrm{C} / \mathrm{EDs}$ also explained that parents can become overinvolved with their children's athletic experience (Johnson et al., 2017), with parents often trying to live through their children. This issue is not uncommon; athletic administrators consider parents living through their children as one of the most consistent problems they face, and when parents become over-involved, their actions reach the coaches and referees (Johnson et al., 2019):

I think, especially in Indiana, and especially when it comes to basketball, we tend to get very intense with things like that. Parents can take the fun, and take the enjoyment, and the purpose out of (sport). Your kids are supposed to be learning about teamwork and leadership, and their role on the team, and parents lose track of that. (Participant 1)

\section{Omnipresent Private School Influence on Education}

The omnipresent public/private influence that was constant throughout the interview processes, as well as the misunderstanding of recruiting, resources, and private school funding, supports prior literature that public school parents are likely underinformed on these topics (James, 2013; Johnson et al., 2019; Johnson et al., 2017). As one state interscholastic C/ED stated, "The overriding thing in my mind with our general public uproar is that they don't understand how a private school works" (Johnson et al., 2017, p. 269). National athletic administrators consider educating parents as the biggest issue they face on a consistent basis (Johnson et al., 2019).

Some participants indicated the IHSAA needs to further address private school dominance as a whole, yet failed to acknowledge that much of the private 
school success comes from a consistently strong group of private schools that have repeated success annually (Johnson et al., 2014). Participants generally stated that private schools' lack of boundary restrictions lead to recruiting and that the IHSAA needs to put more emphasis on transfers, despite the policies already in place (Johnson et al., 2018). Additionally, every state has people who disagree with the $\mathrm{CB}$ policy, and implementing a new policy is often faced with a multitude of legal hurdles (Johnson et al., 2017; McCurdy, 2018). Perhaps the most logical solution for interscholastic athletic governing bodies is to increase their educational outreach regarding their missions and policies, especially when considering the scarce amount of communication between parents and athletic administration (Camire, 2014). Despite efforts to provide information online, good intentions can be undermined by those who misconstrue or perpetuate incorrect information through social media or other online platforms (Johnson et al., 2019; Johnson et al., 2017). Even some of the parents suggested that more education could reduce these issues: "I think the more educated people that you have involved, the more success you're going to have as a program" (Participant 10). Participant 6 agreed and believed that the IHSAA should provide more education:

So, I know there's a statement about sportsmanship... I know that there's also information about concussions. We get some paperwork. I look at it and sign it and pay a lot of attention to it.
If they could do the same with private schools or the TSF, I think it would solve a lot of their problems.

\section{Limitations}

This study offered new perspectives on interscholastic $\mathrm{CB}$, but includes limitations. First, $\mathrm{CB}$ policies differ by state (Johnson et al., 2015). While this study focused on one policy imposed by the IHSAA (Johnson et al., 2014), each state has its own unique CB landscape with its own unique policies (Cohen, 1997; Hale, 2017; Johnson et al., 2017; Popke, 2012; Smith, 2018; Thomas, 2017). The combination of different states and policies could generate different perspectives than ones found within Indiana. Second, participants were limited to rural public high schools within small to somewhat large enrollment classifications. Parents from the largest enrollment classifications and metropolitan locations were not included. Third, due to purposive sampling and stakeholder roles as parents, participants likely had strong opinions on the topic. Parents with children who have less experience in post-season competition may feel differently. Finally, examining perceptions of private school parents was beyond the scope of this study. By including these additional parents (or other stakeholders from these schools) future research could provide additional $\mathrm{CB}$ perspectives.

\section{Conclusion}

Parents are an important influence on their children's interscholastic athletic 
experience. Prior to this study, anecdotal information has suggested that parents of public high school athletes may not understand or appreciate CB (Bosma \& Kunnen, 2001; James, 2013; Johnson et al., 2019; O’Neil, 2015). Findings from this study provide empirical support to confirm a general misunderstanding of $\mathrm{CB}$ policy, and suggest there is an omnipresent consideration of private school influence on parents' opinions of interscholastic CB. A discussion of any $\mathrm{CB}$ variable did not occur without a reference to private schools. Whether it was the participant characteristics, their geographic location, or the disproportionate success of private schools in postseason tournaments, public school parents consistently referenced private schools relative to every facet of interscholastic CB. This omnipresent influence surrounded each CB conversation. While athletic administrators may disagree with some of the conclusions made by public school parents in this study, it is nevertheless important to know how these stakeholders think and feel about $\mathrm{CB}$, which in turn could shape educational resources and policy.

It is important to note, however, that due to the qualitative nature of the study caution should be exercised. While this study provided rich data that could eventually lead to improved CB policies, procedures, and motivations, more research is necessary. Future research should utilize quantitative designs to test the concepts identified within this study. Larger populations in different states with varying levels of public and private school competitions should be targeted. Specifically identifying participants whose children have directly lost to private schools could change the research focus as well. Until such studies are undertaken, generalization to a larger population is unwarranted.

Practically, state athletic association $\mathrm{C} / \mathrm{ED}$ 's should consider expanding upon their educational material for parents or conducting their own follow-up research to this study. The data from this study demonstrated that public high school parents have strong convictions regarding the policies, location, finances, sport culture, and education relative to interscholastic CB. However, it is critical to note that many of the perceptions were underinformed, presumably because they did not understand how private schools operate, or how private schools are integrated into the interscholastic athletic landscape. Strong feelings towards private schools appeared to be exacerbated by participants' experiences watching their children. Despite the omnipresent influence of private schools relative to $\mathrm{CB}$, participants acknowledged that more education about the nuances of private schools would help to bridge the knowledge gap for stakeholders on both sides of the public/private divide (Johnson et al., 2019; Johnson et al., 2017).

\section{References}

Aronson, J. (1995). A pragmatic view of thematic analysis. The Qualitative Report, 2(1), 1-3. Blackburn, M., Forsyth, E., Olson, J., \& Whitehead, B. (2013). NLAAA's guide 
to interscholastic athletic administration.

Human Kinetics.

Bosma, H. A., \& Kunnen, E. S. (2001).

Determinants and mechanisms in ego

identity development: A review and

synthesis. Developmental Review, 21(1),

39-66. https://doi.org/10.1006/

drev.2000.0514

Braun, V., \& Clarke, V. (2019). Thematic analysis. In P. Liamputtong (Ed.), Handbook of Research Methods in Health Social Sciences (pp. 843-860). Springer. https://doi.org/10.1007/978-981-105251-4_103

Budzinski, O. B., \& Pawlowski, T. (2017). The behavioral economics of competitive balance: Theories, findings, and applications. International Journal of Sports Finance, 12(2), 109-122.

Camire, M. (2014). Youth development in North American high school sport: Review and recommendations. Quest, 66(4), 495-511. https://doi.org/10.10 80/00336297.2014.952448

Caporale, T., \& Collier, T. C. (2015). Are we getting better or are they getting worse? Draft position, strength of schedule, and competitive balance in the National Football League. Journal of Labor Resources, 36(3), 291-300. https://doi.org/10.1007/s12122-0159206-z

Chen. G. (2018, March). Hello budget cuts, goodbye sports: The threat to athletics. Public School Review. https://www. publicschoolreview.com/blog/hello-budget-cuts-goodbye-sports-thethreat-to-athletics

Coakley, J. J. (2016). Sports and society: Issues and controversies (12 ${ }^{\text {th }}$ ed.). McGraw-Hill.
Cohen, A. (1997, December). Private enterprise. Athletic Business. http:// www.athleticbusiness.com/articles/ article.aspx?articleid $=834$ \&zoneid $=9$

Corso, V. (2018, July 26). PIA A must level field for public, private schools, administrators say. Centre County Gazette. http://www.statecollege.com/news/ local-news/piaa-must-level-field-forpublic-private-schools-administratorssay,1477280/

Creswell, J. W. (1998). Qualitative inquiry and research design: Choosing among five traditions. Sage Publications.

Denzin, N. K., \& Lincoln, Y. S. (1994). Handbook of qualitative research. Sage Publications.

Dittmore, S. W., \& Crow, C. M. (2010). The influence of the Bowl Championship Series on competitive balance in college football. Journal of Sport Administration and Supervision, 2(1), 7-19.

Epstein, T. L. (2008). Prep plus: Evaluating the motivations for and effects of enrollment multipliers and other measures in high school sports. Texas Review of Entertainment and Sports Law, 10, 1-22.

Forrest, D., \& Simmons, R. (2002). Outcome uncertainty and attendance demand in sport: The case of English soccer. The Statistician, 51(2), 229241. https://doi.org/10.1111/14679884.00314

Fort, R., \& Maxcy, J. (2003). Competitive balance in sports leagues: An introduction. Journal of Sports Economics, 4(2), 154-160. https://doi.org/10.117 7/1527002503004002005

Fort, R., \& Quirk, J. (1995). Cross-subsidisation, incentives, and outcomes 
in professional team sports leagues. Journal of Economic Literature, 33, 12651299.

Gaskins, B. (2012). Football tourney is a joke. IHS AA needs to put public schools in separate class. Kokomo Tribune. http://www.kokomotribune.com/ sports/x1951906318/GASKINSFootball-tourney-is-a-joke

Hale, J. (2017, July 12). FHSAA and area coaches weigh in on public versus private high school sports debate. WJHG. https:// www.wjhg.com/content/sports/Area-coaches--434138903.html

Himmelsbach, A., \& Thamel, P. (2012, June 25). Middle school basketball's fiercest recruiting battleground. The New York Times. https://www.nytimes. com/2012/06/26/sports/basketball/ in-washington-area-private-highschools-fight-for-basketball-recruits. html

Humphreys, B. R. (2002). Alternative measures of competitive balance in sports leagues. Journal of Sport Economics, 3(2), 133-148. https://doi. org/10.1177/152700250200300203 IHSAA. (2019). Enrollments \& classifications. http://www.ihsaa.org/Schools/ EnrollmentsClassifications/tabid/1822/Default.aspx

James, J. T. (2013). How much does a private school student count? A critical analysis of the athletic multiplier. Catholic Education: A Journey of Inquiry and Practice, 10(4), 408-432.

Johnson, J. E., Forsyth, E., Whisenant, W. A., \& Stoffer, G. W. (2019). Parents and interscholastic sport: A mixed-method approach to identify salient issues. Managing Sport and Leisure, 24(1), 59-77. https://doi.org/10. 1080/23750472.2019.1583077

Johnson, J. E., Giannoulakis, C., \& Scott, B. F. (2017). Interscholastic competitive balance: An examination of state athletic association administrators. Journal of Sport Management, 31(3), 256-274. https://doi.org/10.1123/ jsm.2016-0226

Johnson, J. E., Lower, L. M., Scott, B. F., \& Manwell, A. K. (2018). The public/ private divide: An analysis of American law relative to recruiting and transfer policies in interscholastic athletics. International Journal of Sport Policy and Politics, 10(3), 493-508. https:// doi.org/10.1080/19406940.2018.142 8214

Johnson, J. E., Pierce, D. A., Tracy, D. R., \& Haworth, G. J. (2014). The public vs. private debate: A case study of Indiana interscholastic sport and the Tournament Success Factor. Global Sports Business Journal, 2(3), 44-62. Johnson, J. E., Tracy, D. R., \& Pierce, D. A. (2015). National review of interscholastic competitive balance solutions related to the public-private debate. Journal of Amateur Sport, 1(1), 29-51. https://doi.org/10.17161/jas. v1i1.4920

Khandkar, S. H. (2017). Open coding. University of Calgary Computer Science. http://pages.cpsc.ucalgary.ca/ saul/ wiki/uploads/CPSC681/open-coding.pdf

Kvale, S. (1996). Interviews: An introduction to qualitative research interviewing. Sage Publications. 
Maguire, M., \& Delahunt, B. (2017). Doing a thematic analysis: A practical, step-by-step guide for learning and teaching scholars. All Ireland Journal of Teaching and Learning in Higher Education, 8(3), 3351-3364.

Monahan, S. (2012, January). Public vs. private schools-Leveling the playing field. High School Today, 5(4), 12-14.

National Center for Education Statistics (2013). Number of public school districts and public and private elementary and secondary schools: Selected years, 1869-70 through 2010-11. Retrieved http:// nces.ed.gov/programs/digest/d12/ tables/dt12_098.asp

National Center for Education Statistics (2018). Fast facts. https://nces.ed.gov/ fastfacts $/$ display.asp?id $=372$

Neale, W. C. (1964). The peculiar economics of professional sports. The Quarterly Journal of Economics, 78(1), 1-14. https://doi. org/10.2307/1880543

NFHS (2018). High School participation increases for the $29^{\text {th }}$ consecutive year. https://www.nfhs.org/articles/ high-school-sports-participation-increases-for-29th-consecutive-year/

O’Neil, W. (2015). Parents play crucial role in helping students achieve success. NFHS. https://www.nfhs.org/articles/parents-play-crucial-role-in-helping-students-achieve-success/ $\mathrm{k}$

Patton, M. Q. (2002). Qualitative research and evaluation methods. Sage Publications.

Popke, M. (2012, December). Demand to close gap between public, nonpublic schools increases. Athletic Business. http:// www.athleticbusiness.com/articles/ article.aspx?articleid $=3938 \&$ zoneid $=9$ Rottenberg, S. (1956). The baseball players and labor market. Journal of Political Economy, 64, 242-258. https://doi. org $/ 10.1086 / 257790$

Smith, A. (2018, February 26). Private vs. public an issue in high school athletics. The Gazette. https://www. thegazette.com/subject/sports/ iowa-prep-sports/football/private-vspublic-an-issue-in-high-school-athletics-20180226

Sokeland, J. (2012, August 22). Providence faces "penalty" for its soccer success. Courier-Journal. http://blogs.courier-journal.com/indianahss/2012/08/22/ providence-soccerpossibly-penalized-by-ihsaa-success-factor/

Taylor, S. J., \& Brogdan, R. (1984). Introduction to qualitative research methods: The search for meanings. John Wiley \& Sons.

Thomas, B. (2017, June 25). Private vs. public schools: Will there soon be another change in the AHSAA athletic playing field? AL.com. http:// highschoolsports.al.com/news/ article/4306251179099043292/ private-vs-public-schools-will-theresoon-be-another-change-in-the-ahsaaathletic-playing-field/

Thomas, D. R. (2006). A general inductive approach for analyzing qualitative evaluation data. American Journal of Evaluation, 27(2), 237-246. https:// doi.org/10.1177/1098214005283748

Zimbalist, A. (2002). Competitive balance in sports leagues: An introduction. Journal of Sports Economics, 3(2), 111-121. https://doi. org/10.1177/152700250200300201 


\section{Interview Script}

\section{Appendix}

1. Please tell me your name and the sport(s) your child/children participate(d) in.

2. Can you talk about your child's experience in their sport, especially their experience in the postseason state tournament?

3. What are some of the biggest problems you see in high school sport (if any)?

4. What are your current beliefs about the IHSAA?

a. What works or doesn't work within the current structure?

b. Do you believe there is enough education for parents regarding the structure of high school sports?

5. What are your opinions on the postseason state championship tournament?

a. Do you believe that its current format is fair for all schools participating?

b. Are any sports (especially your child's sport) treated differently?

6. Do you believe that every school competing has an equal chance at winning the state championship? Explain your reasoning.
7. Think about the most competitive schools within the sport your child or children compete(d) with in the postseason tournament. What are the most common traits or characteristics that these schools possess?

8. Do you know what the Tournament Success Factor is?

a) How would this impact your child's sport?

b) Does this seem like a fair policy?

c) Are there better ways that competitive balance could be achieved?

9. Do you believe there are any differences between public and private schools? If so, what are they?

a. Have you ever heard that private high schools recruit student-athletes?

10. What advice would you give Indiana's state athletic commissioner to ensure equity and fairness for teams competing for a state championship?

a. How could they improve on communication and education for athletes and parents?

b. Should there be something done to address private school success? 